\title{
Mixed Arable 'Farm on which Seed Production is Prominent
}

\author{
G. J. Slater, Hilton, South Canterbury.
}

THE demand for an ample supply of 1 pasture seeds has always existed in areas where arable farming is practised and the demand for good seed has increased with the knowledge of the production and life of pastures. As a result there is now a fairly stable demand for more highly productive types and 'strains of seed for both resowing arable land and for resowing those herbage production. As pasture-seed production demands simillaf conditions of soil climate, and contour as the production of cereals and other the production it is natural and other terbury should be the largest Canterbury should be the largest producer of pasture seeds, the main kinds.

'In order that the present and, if possible, the future position of pastureseed, production and its relationshïp to arable farming is necessary to understand the facts leading up to the present situation.

Up to about 1930 the method used by Canterbury farmers for sowing pasture was to sow down with wheat or other cereal or rape or turnips about "a bushel of "ryegrass" with 2 or $31 \mathrm{~b}$. of red clover. One of the areas sown $\therefore$ was: left for ryegrass seed in the summer of the following year and after ing year's req uirements the surplus ing year's requirements the surplus seed after an early hay crop, and white clover was sometimes taken in suit-

able seasons from stubble areas which had been left over from the previous harvest.

In short, pasture was considered secondary to cropping, and pasture seed was taken only to save the expense of buying. This was the situation up to 1939 ; paddocks were sown down only to give them a spell, the use of

lime was considered unnecessary, and superphosphate was still regearded by most farmers only at the best as a stimulant and not a necessity to crops.

\section{- Production of-Ryegrass Seed-}

Ryegrass-seed production in Canterbury received its first modern impetus with the sowings of "Hawke's Bay" ryegrass sown under contract about 1929-30. As a result of this the pendulum swung back, and but for the ffort would have ended in disaster; 'even as it was it retarded development for some Years. The pure sowing of ryegrass without clover on cropped land, without lime, and with little phosphate was, as is well known, the cause. In' fact the only feature which. kept the project alive was the price, another stimulant which ately to react against the true develop its relationship to arable farming.

During the boom-price period pas-
to relationship to arable farming. ture seeds were produced for their return per bushel or pound of seed rather than their yield per acre. Machine-dressing loss and quality were forgotten in what can be termed the mad rush for the buried treasure of small seeds, a treasure which only in the in the collapse of the market, the causes of which were receding prices, record areas, bad harvesting conditions, and disease.

\section{Period of Formation}

Those 15 years of alternating periods of hope and despair can be regarded now as a period of formation and development during which the true relationship between seed production and arable farming was straightened out. Lessons were being learnt and applied throughout this period which have gradually placed seed production on arable land into. its true perspective.

It has been proved that, first, pasture-seed production on a catchcrop basis as a quick revenue earner is risky,- and, secondly, that it is not sound practice to devote the farm wholly to seed growing and to ignore the use of livestock in arable farming.

Like any other business, whether farming or commercial, seed production resolves itself into one routine Certain cperations must be carried out annually and throughout the farming year to ensure continuity in production and revenue and to avoid failures.

It has been claimed, and rightly so, that on many farms throughout the 15-year period from 1930 seed growing reduced the areas, of crops and the number of sheep carried and fat the number of sheep carried and fat lambs produced. on those farms (and they may still be in the majority) they may still be in the majority) used. On farms where seed production has been dovetailed. into arable farming combined with sheep raising and where the lessons learnt through the development period 'have been applied land fertility, crop production, and carrying capacity have improved and revenues have increased.' 


\section{Use of Built-up Fertility}

The basis of sound arable farming is a constant annual supply of firstvear harvest paddocks of perennial, short-rotation, or Italian ryegrasses and second year paddocks of red or white clover sown under conditions suitable to the establishment and growth of pasture seed-conditions which make full use of built-up fer-

- tility by adequately-limed and fertitivation and which encourage the crop and make the maximum use of the initial vigour which all plants and animals possess in youth.

The basis of all first-year haryests Is, of course, yield, and high yield has been found to be associated with high purity and low and, in the case of the ryegrasses, good germination or less susceptibility harvests mean a fairly short-lived period that the paddocks are down to pasture if any-area-is being saved? but this procedure fits in comparatively winter and fattening feed have to be grown because they are essential or as a safeguard. In order to maintain continuity it, is necessary that after two seed crops, one of ryegrass and ne of clover, the paddocks are still their lives, which depend on the length of the rotation.

\section{Production' Programme Intensified}

From this it can be seen that, provided the saving of pasture seeds on an arable farm is carried out on the proper basis, it intensifies the programme of production. Though as rule the length of life of a pasture is combined in the programme, the pasture never reaches the stage of becoming worn out and unproductive. The system also ensures that the sowitig of a paddock to grass becomes the final operation of the cycle for that area. This means that all the effort goes into seeing that the procedure is successful, so that pasture establishment becomes of first priority instead of being pushed into

the background as in former days. Livestock numbers and croprea and liming and topdressing area become more stable; a condition which is ultimately reflected in the wellbeing of the farm.

The closing of paddocks for seed takes place when grass growth is starting to make its maximum development and surplus feed is beginning to show,. and this is an advantage,. for it is generally recognised spring and early-summer capacity is not wise. Of course, this surplus could be made into hay, but the revenue obtained from an average seed nue obtained from an average seed crop has been found to be one of the best ways of balancing the budget on terbury. In arable farming the whole secret of Success seems to be in not letting specialisation i $n$ particular dominate the position to the detriment of the others. Other mere, the difficult to restore. The tendset it 11 the seed producer is, of course, to save too great an area for seed, the temptation being to save older paddocks as well as newly-sown ones, This procedure reacts against the well-being of the livestock on the lambs suffer. Sometimes grazing is obtained elsewhere, but this is not generally satisfactory.

\section{Improving the Land}

From- experience it appears that when the farm on which it is practised is on what can be termed a rising plane of fertility. The difficulty is more the improving of the land 'so that the seed can be grown rather than the actual growing of the seed, which is more or less the result of experience from season to season.' Under lowfertility conditions it is difficult to obtain harvestable and payable crops, and in the case of ryegrass it is well known that it takes quite "a bit out cf the ground." At the other end of conditions, it is again difficult to obmuch grayth and consequently poor ripenin and difficult harvesting condithons. Ir must be remembered that ing are types that have been produced for leaf rather than for seed; they. like high-fertility conditions, making leaf to the detriment of the seed yield.

The creating of this upward trend of fertility is therefore as necessary in seed production as it is in every phase of farming if success is to be achieved.

The beginning of a set rotation, including seed production on arable farms in Canterbury, will-be-governed

by the set-up of the individual farm, in which consideration has to be given to contour, fertility, and previous farming practice.

On a farm where a rotation that includes roots and fodder crops, peas, ground' is followed by cereals a start pasture for seed production after the cereal crop. The basis is a fallow from autumn to autumn, coupled with 
good cultivation, adequate liming, a liberal manuring, and the use of good seed mixture. Good husbandry aganed through expernence under averpasture -and seed crops to be obtained.

The annual area sown to new pasture should correspond as near as practicable to the annual area broken up out of old pasture, which for al practicable purposes can be taken as a tenth of the area of the farm. Once ploughed, the area will be out of grass for approximately 3 years. This is under cultivated crops and fallow. a tenth in first-year ryegrass for seed and a tenth in second harvest as white or red cloyer for seed. This amounts in all to about half the holding, leaving the other half for grazing purposes in 2-to g-year-old pasture.

The stocking of the grazing pasture hould be up to full capacity, reliance being placed on the supporting feed to be obtained from tlie first- and second-year seed stands in times of scarcity, etc. programme of work there will be few within the capacity of a modern mechanised plant on a Canterbury arable farm

\section{Pasture Establishment}

The practice adopted by the writer for pasture establishment, with the aim of producing as great a yield of quality seed as possible from the area quality seed as possjble from the

Thorough preparation of the seedbed with good cultivation is necessary after a lengthy fallow. The final workings should be of a surface nature only, and at least $1 / \mathrm{m}$ of carbonate of lime should be applied before the firming of the seed-bed. It will be seen that in combining seed, in late summer or autumn so that the and the highest possible yield of ryearass seed will be obtained.

grass seed will be obtained. Were pennial ryegras is bein. used broadcasting a mixture of 301 b. of perennial ryegrass with $31 \mathrm{~b}$. of white clover and $21 \mathrm{~b}$. of crested dogstail per acre is generally favoured. usually drilled at the rate of $251 \mathrm{~b}$. to- gether with $41 \mathrm{~b}$. of 'broad or Montgomery red clover. For short-rotation ryegrass used either with red or white clover drilling and broadcasting seem to find equal favour. The method used hy the writer is to drill a bushel of ryegrass with a liberal sowing of superphosphate and to broadcast about $\frac{1}{2}$ bushel of ryegrass with $31 \mathrm{~b}$. of white clover or $4 \mathrm{Ib}$. of red clover and $21 \mathrm{~b}$ of crested dogstail through the front box of the drill in late February or early March.

\section{In seed production it is, of course, essential that the highest grade of Certified seed obtainable is used in all the species sown in}

\section{the mixtures.}

The management of the newly-sown areas in autumn and early winter is to stock as soon as possible and to graze off quickly and'-allow time for recovery. In spring before the closing of the area the practice is not to hard graze, but rather to lighten the grazing just to keep the flaggy top off and give the plants a chance to bring every tiller to a seed head. Finaly, the stock should be taken off when definite signs of heads are appearing. By this time growth will have reached a height of 6in. or more and will almost certainly mean a lodged crop.. which, according to an old saying, "ruined" no mields result, with which are associated higher germination.

The treatment of the final closing different; treatment can be harsher and shutting up later. On average moist, clay subsoils a good sprinkling of flowers appears before closing of the areas. The right time to shut up the seed-production areas is learnt from experience and a thorough understanding of the soil type and rain-

For the first 2 or 3 years after the beginning of such a programme there appears to be nothing but hard work and heavy expenditure in fuel, fertilisers lime, and seed. But once the asm begins to increase. The result of the work begins to show in an improved holding and increased returns, the farmer begins to see that he is making "progress, every step is of interest and it takes a major upset for cycle. 